
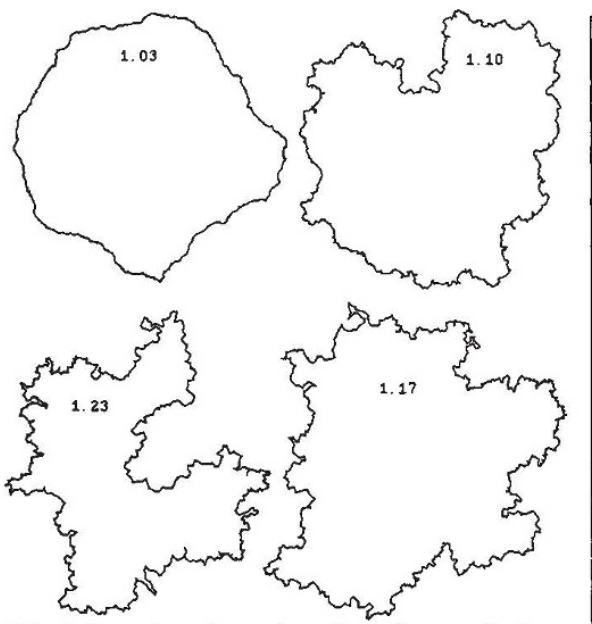

FIG. 2 A random fractal outline (from ref. 5).

but in the new work ${ }^{1.2}$ by Mecholsky and co-workers, their original samples are subjected to a proper fractal analysis, using both horizonal and vertical methods of analysis. It is quite clear that the fracture toughness, $K_{c}$, of chert increases as the fractal dimension increases - as the fracture surface becomes rougher. This is the exact converse of what was found for maraging steel. (The relationship for chert is in the form of a linear log-log plot of $K_{c}$ against fractal dimension.)

The authors also indicate, by means of a figure relating the fractal dimension of the fracture surface to fracture toughness for several ceramics (oxides, silicates, chalcogenides) that this form of relationship is universal for such highly brittle materials, though the results bunch into several distinct material groups rather than falling along a single master line. This research is itself a continuation of earlier work ${ }^{\text {? }}$.

\section{Bacteria that thrive in toluene}

\section{Howard Goldfine}

TOLUENE is widely used in the laboratory to permeabilize and kill bacteria. Thus, the isolation of a bacterial strain described by Inoue and Horikoshi on page 264 of this issue', which not only resists the toxic actions of toluene, but grows luxuriantly in the presence of emulsions containing up to 50 per cent of this solvent, represents a significant achievement. In a rich medium, Inoue and Horikoshi find that growth in the presence of toluene is about two-thirds as rapid as that obtained in its absence. It should, however, immediately be noted that the newly isolated strain only tolerates toluene rather than using it as an energy source.

The organism, identified as a strain of the gram-negative aerobe Pseudomonas putida, an organism known for its protean degradative capabilities, was isolated after screening 750 soil samples collected in Japan. The only hint concerning the site
We thus have the intriguing fact that the relationship between fracture roughness (fractal dimension) and fracture toughness is diametrically opposite for ductile fracture (maraging steel) and for brittle fracture (chert and polycrystalline ceramics). For chert, where fracture is governed by the spreading of cracks, the toughening influence of factors making for rough fractures has been qualitatively explained. For ductile fracture, which can take place by the progressive creation, growth and merging of minute voids, the relationship is clearly different. Mandelbrot et al. ${ }^{8}$ seek to interpret their findings in terms of percolation concepts applied to the filaments remaining intact between voids, but it must be said that their argument is not easy to follow. It is to be hoped that in future work, Mecholsky and colleagues will address the piquant distinctions between ductile and brittle fracture which these studies have uncovered.

Robert W. Cahn is in the Department of Materials Science and Metallurgy, University of Cambridge, Pembroke Street, Cambridge CB2 3QZ, UK.

1. Mecholsky, J.J. \& Mackin, T.J. J. Mater. Sci. Lett. 7, 1145 $1147(1988)$

2. Mecholsky, J.J., Passoja, D.E. \& Feinberg-Ringel, K.S. Am. Ceram. Soc. 72, 60-75 (1989).

3. Mandelbrot, B.B. The Fractal Geometry of Nature (Freeman, New York, 1982)

Gleick, J. Chaos: Making a New Science 94-118 (Heinemann, London, 1988)

5. Russ, J.C. in Encyclopedia of Materials Science and Engineering Suppl. Vol. 1 (ed. Cahn, R.W.) 169-175 (Pergamon, Oxford, 1988).

6. Underwood, E.E. \& Banerji, K. Mater. Sci. Engng. 80, 1-14 (1986)

7. Mecholsky, J.J. \& Passoja, D.E. in Fractal Aspects of Materials 117-119 (Mater. Res. Soc., Pittsburgh, 1986).

Materials $117-119$ (Mater. Res. Soc., Pittsburgh, 1986). 308, 721-722 (1984)

9. Beauchamp, E.K. \& Purdy, B.A. J. Mater. Sci. 21, 1963 1966 (1986). enzymes of the catechol meta cleavage pathway ${ }^{3}$. It would seem to be just a short step to bring together these degradative resistance characteristics. The isolated strain is also resistant to styrene, $p$-xylene, ethylbenzene, cyclohexane, $o$-dichlorobenzene, propylbenzene and various alkanes up to isooctane, thus there is wide scope for producing both solvent-tolerant and solvent-degrading strains. The marriage of these two desirable traits may be less than harmonious, however. The alterations in the cells of the toluenetolerant strain that make growth in solvents possible could shield the cell from these solvents so perfectly that little penetration to the locations of degradative enzymes would be possible.

The authors of the paper in this issue, one of whom is a member of the Superbugs Project of the Research Development Corporation of Japan, have begun a genetic analysis of the solvent resistance of $P$. putida. They have isolated a series of mutants of their new strain that are not resistant to toluene, but retain resistance to solvents of lower polarity in the order toluene $>p$-xylene $>$ cyclohexane $>$ hexane.

By examining the partitioning index of these and other substances in a standard octanol:water mixture, they can predict accurately the resistance of these mutant strains to other compounds in the polarity scale. In addition to mutant strains of $P$. putida, they can order other microorganisms in a similar hierarchy of solventtolerance, in which growth in a solvent of a given polarity indicates tolerance to solvents of lower polarity. Genetic analysis combined with biochemical and morphological studies should provide useful insights into the nature of solvent tolerance in these bacteria.

The outer membrane of gram-negative bacteria is important in determining the penetration of hydrophobic molecules through cell membranes, and consequently in determining the resistance of these bacteria to dyes, detergents, bile salts and hydrophobic antibiotics. Mutations in the structure of the lipopolysaccharide of the outer membrane can profoundly affect permeability of these molecules, but these effects are complicated by concomitant changes in the amounts of specialized pore-forming, outer-membrane proteins ${ }^{4}$. Studies of the outer membranes of these solvent-resistant strains of $P$. putida may be rewarding.

Howard Goldfine is Professor of Microbiology at the University of Pennsylvania School of Medicine, Philadelphia, Pennsylvania 19104. USA.

formation is clearly desirable. $P$ putida contains chromosomal genes encoding the enzymes involved in the degradation of aromatic compounds by the so-called ortho cleavage pathway, and strains have been isolated that contain the common TOL plasmids encoding the genes for the

1. Inoue, A. \& Horikoshi, K. Nature 338, 264-266 (1989).

2. Gibson, D.T. \& Subramanian, V. in Microbial Degradation of Organic Compounds (ed. Gibson, D.T.) 181-252 (Dekker. New York, 1984).

3. Bayly, R.C. \& Barbour, M.G. in Microbial Degradation of Organic Compounds (ed. Gibson. D.T.) 253-294 (Dekker. New York, 1984).

4. Nikaido, H. \& Vaara, M. Microbiol. Rev. 49, 1-32 (1985) 